\title{
Managers' Open Innovation and Business Performance in SMEs: A Moderated Mediation Model of Job Crafting and Gender
}

\author{
Fouzia Hadi Ali ${ }^{1}$, Muhammad Ali ${ }^{2, *}$, Sania Zahra Malik ${ }^{2} \oplus$, Muhammad Ali Hamza ${ }^{3}$ and \\ Hafiz Fawad Ali 4 \\ 1 Hailey College of Commerce, University of the Punjab, Lahore 54000, Pakistan; fozia.hcc@pu.edu.pk \\ 2 Institute of Business Administration, University of the Punjab, Lahore 54000, Pakistan; \\ saniazmalik@ibapu.edu.pk \\ 3 UVAS Business School, University of Veterinary and Animal Sciences, Lahore 54000, Pakistan; \\ mahamza@uvas.edu.pk \\ 4 Department of Management Sciences, University of Okara, Okara 56300, Pakistan; fawadali@uo.edu.pk \\ * Correspondence: mali@ibapu.edu.pk
}

Received: 2 September 2020; Accepted: 16 September 2020; Published: 17 September 2020

\begin{abstract}
There is growing acceptability in redesigning jobs to achieve goals and objectives nowadays Employees who indulge in exploiting and exploring opportunities for the business tend to craft their jobs, which can help to enhance business performance. This study aims to examine that how ambidextrous managers in small and medium enterprises (SMEs) craft their tasks as a strategy for open innovation to enhance business performance. This study also attempts to assess the moderating role of gender in evaluating the relationship. Simple random sampling is used to administer a structured questionnaire to 650 operations managers employed in service-sector SMEs. The findings reveal that, when male managers involve in explorative and exploitative activities, they tend to craft their jobs more as compared to females. In turn, when jobs are redesigned, it brings a positive impact on business performance as perceived by the managers. The study provides implications for the policy makers with regard to device measures to enhance the job crafting capacity of managers with specific attention to female managers in the case of small and medium enterprises. The present study provides a novel explanation of the relationship between manager ambidextrous behavior and business performance through the mediation of job crafting among top managers working in small and medium organizations, with an overarching view of gender.
\end{abstract}

Keywords: open innovation; manager ambidexterity; job crafting; perceived business performance; gender; small and medium enterprises

\section{Introduction}

In 2003, Henry Chesbrough coined the term "Open Innovation" (henceforth, OI) that stresses upon an innovative way of thinking to include external knowledge gathered through the suppliers, customers and institutions (i.e., explorative or inbound open innovation) that aims to introduce new ways of achieving organizational effectiveness by offering new products or services in the market (i.e., exploitative or outbound open innovation) [1]. However, even before presenting the ground for a paradigm shift of $\mathrm{OI}$, the scientific discussion on balancing explorative and exploitative activities within the firms was started by James G. March (1991) in his seminal work that indicates some capabilities that may be needed to manage the trade-offs between the exploration and exploitation of the resources during the innovation process adopted by the firms [2]. However, a plethora of studies focus on different dimensions, antecedents and consequences of OI. Still, there is a dearth of 
literature that focuses on the individual ambidextrous competencies among executives or managers that promote OI [3]. However, while addressing the individual competencies, it is important to observe that organizations' cultures play a vital role in ascertaining whether the managers can exploit and explore opportunities that are advantageous to the organization [4]. They claim that managers are the "architects" of "ambidextrous courses of action." They also argue that the contextual factors of organizations, such as formalization, maturity (the organization's age), and span of control can play a vital role in assessing whether managers are allowed to introduce change in the course of their duties. In the past, most studies on OI focused on larger firms [5,6]. However, considering the fact that most of the businesses in any economy are comprised of small and medium enterprises (SMEs) [6], recently researchers have been focusing on the implementation of OI on SMEs. However, the challenge remains in addressing OI, as a plethora of literature that indicate various terminologies and contributions in the context of SMEs. Such a challenge has led to unclear contributions in this field [6]. Since SMEs are more flexible, less bureaucratic and fast in decision-making as well as in reacting to market changes, open innovation is a feasible innovation strategy that the managers can adopt. Such characteristics can enable smaller enterprises to benefit more through OI than the larger enterprises [7]. This view necessitates an examination of the role managers play in exploring and exploiting opportunities in the context of small and medium enterprises (SMEs), as most studies focus on larger organizations [8-10].

In general, SMEs have fewer formal organizational structures [11]. Besides this, larger organizations, managers require lesser personal interdisciplinary competencies. However, as the size of businesses change in different ways-such as SMEs possessing scarce resources-the SME managers have to assume more complex hybrid ambidextrous roles while running day-to-day business to innovate [12]. This enables managers to spend time with valued individuals who can satisfy the psychological need for relatedness [13], and thus motivates them to perform better [14]. This psychological need for relatedness enables managers to seek out enjoyable ways of accomplishing tasks [15], which can be termed "job crafting." It is significant that, when managers indulge in explorative (EX) and exploitive (EP) behavior, they craft their jobs [16] to help enhance business performance [17].

Recently, [18] revealed that female top managers are less effective in leading innovation than their male counterparts. The reason is attributed to the fact that female managers are less open to ideation, risk-taking and exploration activities. However, few studies [19-21] examine the impact of gender differences on SME managers' ambidextrous and job crafting behaviors. Female employees are more involved in explorative and exploitative activities than males [22]. In contrast, [23] report contradicting results that vary across gender. Their results reveal that female employees are more involved in exploitative activities, while male employees are more involved in explorative activities. Therefore, if we argue that there are differences in the ambidextrous behaviors across gender, then it is important to examine how they lead to job crafting behaviors that influence business performance in the context of SMEs.

Additionally, the results of studies on job crafting are equivocal. Some studies $[24,25]$ report that females are more likely to engage in job crafting, while others indicate that males are more involved in job crafting behavior [26]. Our study aims to investigate the ways in which managers tend to alter their tasks, consider who to interact with, and use cognitive abilities to establish new ways to complete tasks [16], which helps to enhance business performance [23]. Moreover, this study approaches the topic by observing how manager behaviors differ based on gender. As a result, this study develops two contributions to the existing literature. First, it investigates managers' involvement in inbound open innovation or explorative activities and outbound open innovation or exploitive activities that induce them to craft their jobs in ways that may enhance business performance, with a particular focus on SMEs. Secondly, it examines the role gender plays in the explorative and exploitative processes. To accomplish this, we draw on social feminism theory to investigate the role managers' gender plays in shaping their behavior and how they differ in exploiting and exploring activities such as job crafting. 
The findings of the study contribute to understanding the significance of the link between gender and job crafting, while connecting manager ambidexterity and business performance.

\section{Theoretical Background and Hypotheses}

\subsection{Ambidexterity}

Ambidexterity was introduced as the simultaneous execution of explorative and exploitative activities [2]. Exploration relates to innovation in products, services, and procedures to identify new opportunities and alternatives [2,27], while exploitation refers to improving the existing competencies, products, services, and procedures [2].

In the past, most studies investigated antecedents of organizational ambidexterity, such as organizational culture [28], leadership [29,30], top management team attributes [31], organizational structure [32], and environmental characteristics [33]. Similarly, various studies also identified the outcomes of ambidexterity, such as export venture performance, customer satisfaction, and perceived organizational performance [32], corporate venture survival [34], and firm performance [35]. However, the literature focuses predominantly on the construct of organizational ambidexterity, with less focus given to employee ambidexterity [36]. Employees in the organization perform the exploitative and explorative activities [37]. Therefore, researchers call for a renewed focus on ambidexterity at the employee level [38].

Employee ambidexterity refers to the employees' balanced pursuit of ambidextrous activities, i.e., explorative and exploitative activities [39]. Employee should specialize in, and capitalize on, activities where they tend to excel [40]. Despite this, very little is empirically known about whether the explorative and exploitative activities undertaken by employees as managers impact business performance [4]. Such a link can only be established by addressing how organizational context can highlight the impact of managers' ambidextrous activities on business performance. For instance, would managers' involvement in exploring and exploiting activities be more beneficial among SMEs, or not? Such insights are still debatable [41].

\subsection{Ambidextrous Behavior in SMEs}

The long-term survival and performance of SMEs are strictly dependent on how well the employees simultaneously explore new opportunities and exploit existing opportunities [42]. Studies also reveal that ambidextrous employee behavior leads to positive performance outcomes [23]. However, the relationship between manager ambidexterity and business performance is still unexplored. This may be because overall organizational ambidexterity is considered a more meaningful indicator for assessing business performance. Nevertheless, it is interesting to note that the behavioral orientation of employees towards ambidextrous activities also contributes to organizational ambidexterity [43], especially in SMEs [11]. This can be attributed to the level of influence employees have in SMEs; their influence is stronger due to the lower levels of hierarchical and authoritative structures [44]. Due to their decentralized decision-making and delegation of authority [11], SMEs allow employees to be directly involved in ambidextrous activities [45]. Comparatively, larger organizations have considerable resources and can employ skilled and professional workers. The availability of resources makes larger organizations competitive regarding innovation for exploring and exploiting opportunities [46].

In contrast, SMEs face challenges exploring and exploiting opportunities due to reduced access to resources [11]. SME employees are exposed to an environment with decentralized decision-making and fewer formal systems. The success of SMEs mostly depends on the knowledge, skills, and experience of employees [47]. Such dependence on employee knowledge, skills, and abilities highlights the prevalence of a psychological need for competence [13]. Besides this, the decentralized decision-making present in SMEs inherently provides managers with sufficient autonomy and self-control [48]. This autonomous orientation can help them internalize the firm's values and objectives by accomplishing their tasks [15], 
and by eliciting proactive behavior [49]. Such proactive behavior helps managers alter their work tasks according to the circumstances.

As a result, this current study focuses on manager ambidexterity as a strategy for open innovation in SMEs and identifies whether or not it leads to improved business performance, with an overarching perspective of the impact of gender differences.

\subsection{Linking Manager Ambidexterity to SMEs' Business Performance}

A range of empirical studies are available that link employees' ambidextrous behavior and firm outcomes in the context of SMEs [17]. They conducted a study on high tech firms operating in China and gathered data from senior managers. Their results revealed that achieving a balance of both explorative and exploitative strategies has a significant impact on SMEs' business performance. However, such results can only be generalized to high tech firms. To develop a more generalizable result, it is important to examine the impact of generalized manager behavior on overall SME business performance, irrespective of a specific industry [23]. This relationship may hold true, as managers' high level of explorative and exploitative behaviors is more beneficial for smaller enterprises [50].

\subsection{The Mediating Role of Job Crafting}

Due to their small scale, some scholars argue that SMEs' success is influenced by the knowledge, experience, and skills of employees and owners [47]. In contemporary organizations, proactive employees are essential for competitive organizations, as they act quickly and efficiently before any situation worsens [51]. Employees can be involved in job crafting behavior, which is a self-oriented proactive behavior wherein employees actively redesign their jobs to fit their needs and preferences. Wrzesniewski and Dutton [49] conceptualize job crafting into three dimensions: task crafting (TC), relational crafting $(\mathrm{RC})$, and cognitive crafting $(\mathrm{CC})$. TC refers to altering the job by changing the type and number of executed activities. RC refers to deciding whom one interacts with on the job, while CC refers to altering the cognitive representation of the job [49]. Thus, being given space to explore and exploit opportunities will provide managers with avenues to redesign their jobs and may enhance SMEs' business performance [4]. As such, this study proposes job crafting as a mediating variable between manager ambidexterity and business performance.

\subsection{The Moderating Role of Gender}

In 2012, a World Development Report (WDR) was published that defines gender as the "constructed norms and ideologies which determine the behavior and actions of men and women" [52]. Besides this, the WDR argues that addressing the possible obstacles to gender equality, especially for females, can help in enhancing productivity and foster long-term development. So, it is important to keep in view the importance of gender and reviewing the literature that argues that females are perceived to be less innovative [18]. This study examines the moderating role of gender based on social feminism theory (SFT), as presented by Black [53]. SFT argues that when males and females have similar endowments, they achieve similar levels of firm performance. However, differences exist in the strategies they adopt, which may vary in terms of cultural, social, and environmental factors within their organizations. Males and females differ in their orientation towards business practices while managing SMEs, noting that males are more inclined to take risks to expand the business and try to lead the market [54]. In contrast, females may have "communal qualities" such as "selflessness" and "concern for others", which may not necessarily improve firm performance. Due to differences in the ways males and females manage SMEs, it is important to observe ambidextrous orientation across gender. Limited literature foregrounds the impact of gender on ambidextrous orientation. Recently, Zuraik and colleagues [18] reveal that males are more involved in exploiting and exploring activities than females. These differences are centered on male managers' willingness to take risks compared to female managers' reluctance to take risks. 
Similarly, job crafting may also vary across different demographic characteristics such as gender. Gender is not significantly associated with job crafting [55], in contrast, and Rudolph and colleagues found that women are, overall, more likely to engage in job crafting than men [24]. While conducting a multi-dimensional study, [22] revealed significant differences in job crafting behavior between genders. The study's findings suggest that males possess a high level of TC behavior, while females exhibit more RC and CC behavior. In contrast, Kim and Lee [20] noted that male employees score highly in RC and CC compared to female employees' high TC scores.

In light of the ongoing discussion regarding the impact of gender on ambidextrous behavior, our study examines the moderating role of gender, while investigating the impact of manager ambidexterity (i.e., exploitation and exploration activities) on SMEs' business performance via the mediating element of job crafting. Our hypotheses are as follows:

Hypothesis 1a. The relationship between EX and BP through TC will be moderated by gender.

Hypothesis $\mathbf{1 b}$. The relationship between EX and BP through $R C$ will be moderated by gender.

Hypothesis 1c. The relationship between EX and BP through CC will be moderated by gender.

Hypothesis 2a. The relationship between EP and BP through TC will be moderated by gender.

Hypothesis $\mathbf{2 b}$. The relationship between $E P$ and $B P$ through $R C$ will be moderated by gender.

Hypothesis 2c. The relationship between EP and BP through CC will be moderated by gender.

The proposed model is outlined in Figure 1.

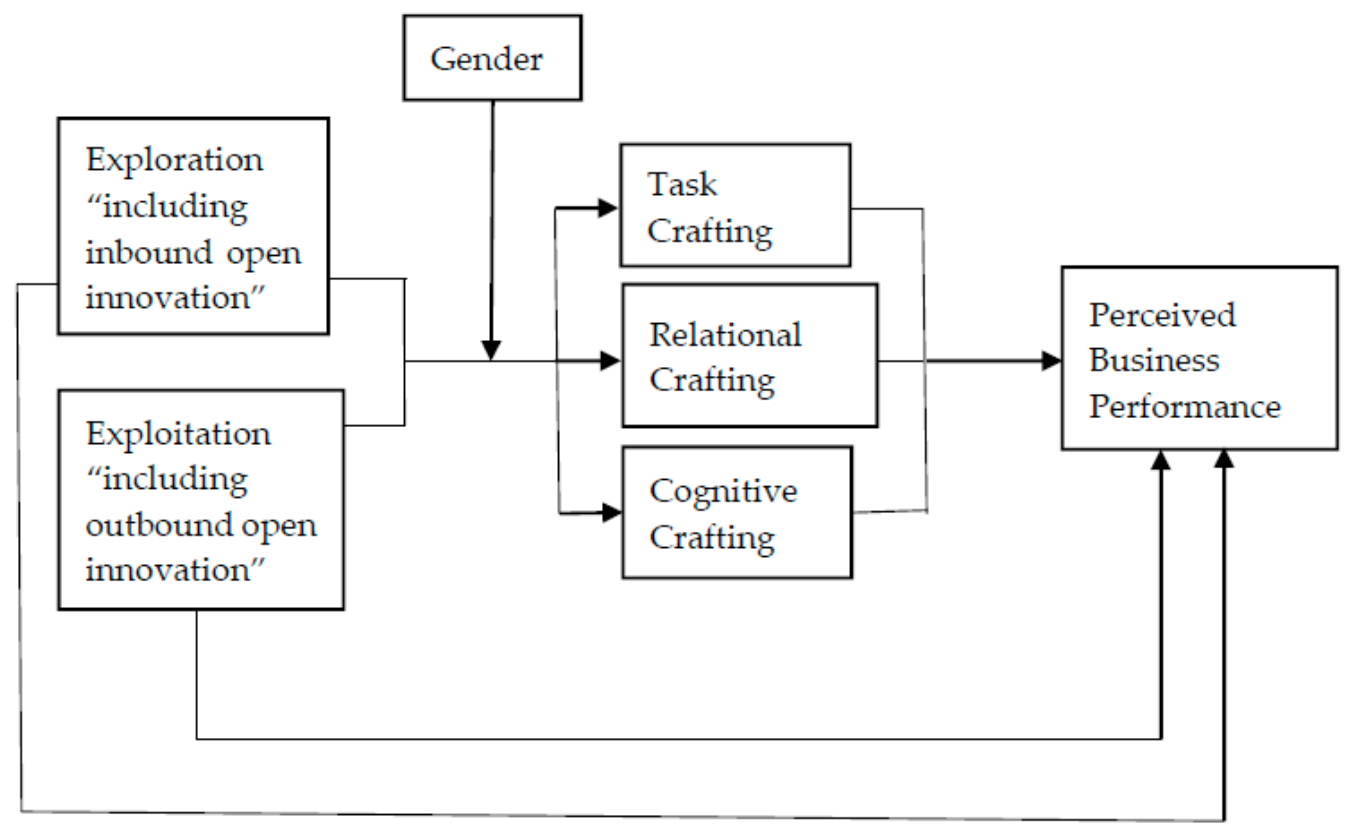

Figure 1. Conceptual Model.

\section{Methodology}

\subsection{Participants and Procedure}

The population examined in this study consists of upper-level managers from service sector SMEs. SMEs in an emerging country like Pakistan contribute $40 \%$ of the annual gross domestic product (GDP) and comprise $90 \%$ of all businesses [56]. Upper-level managers were chosen 
because they supervise the overall affairs of the business. Such affairs include goal-setting, finances, marketing, and many others in the context of SMEs [57]. The list of SMEs was obtained from the SMEDA (Small and Medium Enterprises Development Authority). The list consisted of 4493 firms operating in the service sector. The service sector was selected as it is the most significant contributor to Pakistan's gross domestic product (GDP) (Economic Survey of Pakistan, 2019-2020). Purposive sampling was used. The inclusion criteria included managers who (a) manage and coordinate the overall affairs of the business and are directly monitoring the activities impacting the business performance; (b) relate to different service-related subsectors; and (c) business that have both male and female managers.

Data were gathered via personally-administered questionnaires. During this data collection process, the following procedures were guaranteed: (a) voluntary participation by respondents; (b) data was collected by researchers without involving top management; and (c) the identity of the respondents remained confidential [58]. A total of 650 questionnaires were personally administered to upper-level managers of SMEs operating in service sectors. Due to some incomplete responses, only 590 questionnaires were suitable for further analysis. The sample consisted of $80.3 \%$ male and $13.6 \%$ female respondents. Most of the respondents were permanent employees $(62 \%)$, while the remainder were employed on a contract basis $(28.5 \%)$.

\subsection{Measures}

Employee ambidexterity was measured with 11 items ( 5 items for exploration and 6 items for exploitation) developed by [59] on a 5-point Likert scale, ranging from 1 (to a very small extent) to 5 (to a very large extent). Job crafting was measured on a 5-point scale, ranging from 1 (never) to 5 (very often). A scale developed by Niessen and colleagues [60] was adopted to evaluate job crafting, along with the extended scale developed by Weseler and Niessen [61]. Perceived business performance was evaluated using a scale adapted from Tan and Liu [17]. The adapted scale consisted of 4 items, measured on a 5-point Likert scale, ranging from 1 (strongly disagree) to 5 (strongly agree).

\subsection{Data Analysis Strategy}

Initially, the gathered data were analyzed by using Statistical Package for Social Science (SPSS) Version 21. The data were tabulated and summarized through which descriptive results were extracted. Furthermore, partial least squares structural equation modeling (PLS-SEM) version 3.0 was used to assess the goodness of measures (i.e., reliability, convergent validity and discriminant validity) and testing the structural model. Similarly, multi-group analysis (MGA) was also conducted through PLS-SEM 3.0 to evaluate the gender differences. SPSS Version 21 is helpful in summarizing the data and conducting diagnostic tests that indicate in the appropriateness of the data that is required for model testing. PLS-SEM 3.0 is appropriate to use for testing complex models, and it can deal with categorical variables such as gender.

\section{Results}

\subsection{Common Method Bias}

Harman's single factor test was applied to assess the common method bias in the data gathered. There is a $25 \%$ total variance among the items, which is less than $50 \%$, showing that there is no common method bias among the construct items [62].

\subsection{Assessment of Instrument Validity}

Hair and colleagues [63] suggest testing the instrument's convergent and discriminant validity. The convergent validity was assessed by calculating outer loadings, composite reliability (CR), and average variance extracted (AVE), as per the procedure of Fornell and Larcker [64], with the help 
of smart PLS-SEM. Table 1 shows the value of outer loadings, composite reliability (CR), and average variance extracted (AVE) to test for convergent validity.

Table 1. Means, standard deviations, loading $(\lambda)$, Cronbach's Alpha, composite reliability, and average variance extracted (AVE).

\begin{tabular}{|c|c|c|c|c|c|c|c|}
\hline Construct & Items & Mean & S.D. & Standardized Loadings & Cronbach's Alpha & $\mathbf{C R}$ & AVE \\
\hline \multirow[t]{6}{*}{ Exploration } & & & & & 0.718 & 0.815 & 0.471 \\
\hline & EX1 & 3.148 & 1.20 & 0.780 & & & \\
\hline & EX2 & 3.293 & 1.12 & 0.622 & & & \\
\hline & EX3 & 3.315 & 1.12 & 0.752 & & & \\
\hline & EX4 & 3.424 & 1.10 & 0.582 & & & \\
\hline & EX5 & 3.510 & 1.20 & 0.674 & & & \\
\hline \multirow[t]{6}{*}{ Exploitation } & & & & & 0.637 & 0.785 & 0.423 \\
\hline & EP1 & 3.468 & 1.20 & 0.624 & & & \\
\hline & EP2 & 3.314 & 1.18 & 0.599 & & & \\
\hline & EP3 & 3.302 & 1.15 & 0.657 & & & \\
\hline & EP5 & 3.324 & 1.16 & 0.701 & & & \\
\hline & EP6 & 3.383 & 1.16 & 0.666 & & & \\
\hline \multirow[t]{4}{*}{ Task Crafting } & & & & & 0.610 & 0.744 & 0.493 \\
\hline & TC1 & 3.412 & 1.24 & 0.757 & & & \\
\hline & TC2 & 3.386 & 1.12 & 0.685 & & & \\
\hline & TC3 & 3.669 & 1.47 & 0.660 & & & \\
\hline \multirow[t]{3}{*}{ Relational Crafting } & & & & & 0.680 & 0.794 & 0.660 \\
\hline & $\mathrm{RC} 1$ & 3.573 & 1.16 & 0.747 & & & \\
\hline & $\mathrm{RC} 2$ & 1.158 & 1.21 & 0.873 & & & \\
\hline \multirow[t]{5}{*}{ Cognitive Crafting } & & & & & 0.637 & 0.786 & 0.479 \\
\hline & $\mathrm{CC} 1$ & 3.512 & 1.18 & 0.703 & & & \\
\hline & $\mathrm{CC} 2$ & 3.595 & 1.20 & 0.666 & & & \\
\hline & $\mathrm{CC} 3$ & 3.353 & 1.22 & 0.649 & & & \\
\hline & $\mathrm{CC} 4$ & 3.410 & 1.15 & 0.748 & & & \\
\hline \multirow[t]{5}{*}{ Business Performance } & & & & & 0.713 & 0.823 & 0.537 \\
\hline & BP1 & 3.615 & 1.21 & 0.747 & & & \\
\hline & BP2 & 3.509 & 1.12 & 0.753 & & & \\
\hline & BP3 & 3.624 & 1.10 & 0.716 & & & \\
\hline & BP4 & 3.753 & 1.12 & 0.715 & & & \\
\hline
\end{tabular}

Hair and colleagues [63] state that convergent validity is established when AVE, CR, and outer loadings are higher than $0.50,0.70$, and 0.60 . As seen above, the value of $C R$ and Outer Loadings were within the prescribed range. The values of AVE in EX, TC, and CC were less than the prescribed limit (higher than 0.5), but higher than 0.40; [65] recommend that an AVE value of not less than 0.40 is also acceptable. Therefore, the convergent validity was established as the calculated values of AVE, CR, and outer loadings were within acceptable ranges.

The heterotrait-monotrait ratio of correlations (HTMT) was applied to assess discriminant validity. Discriminant validity ensures that each construct in the structural model measures a different concept $[63,66]$. Table 2 depicts discriminant validity.

Table 2. Results of discriminant validity.

\begin{tabular}{cccccccc}
\hline \multirow{2}{*}{ Sr. No } & Constructs & \multicolumn{7}{c}{ HTMT Correlations } \\
\cline { 3 - 7 } & & $\mathbf{1}$ & $\mathbf{2}$ & $\mathbf{3}$ & $\mathbf{4}$ & $\mathbf{5}$ & $\mathbf{6}$ \\
\hline & Perceived Business & & & & & & \\
1 & performance & & & & & & \\
2 & Exploration & 0.520 & & & & & \\
3 & Exploitation & 0.512 & 0.633 & & & \\
4 & Task Crafting & 0.498 & 0.518 & 0.466 & & \\
5 & Relational Crafting & 0.402 & 0.391 & 0.437 & 0.435 & & \\
6 & Cognitive Crafting & 0.517 & 0.547 & 0.521 & 0.510 & 0.510 & \\
\hline
\end{tabular}


According to $[63,66]$, the HTMT ratio should be less than 0.90 to establish discriminant validity. As the table demonstrates, the HTMT ratio is less than 0.90 among all constructs; discriminant validity was established.

\subsection{Descriptive Results}

The descriptive results in terms of percentage of ambidexterity (i.e., EX and EP) and job crafting (i.e., TC, RC, and CC) prevalent in SMEs are shown in Table 3.

Table 3. The percentage level of ambidextrous and job crafting behaviors.

\begin{tabular}{cccc}
\hline \multirow{2}{*}{ Constructs } & \multicolumn{3}{c}{ Percentages } \\
\cline { 2 - 4 } & Low & Medium & High \\
\hline Task Crafting (TC) & $14.4 \%$ & $32.7 \%$ & $52.9 \%$ \\
Relational Crafting (RC) & $10.3 \%$ & $25.6 \%$ & $64.1 \%$ \\
Cognitive Crafting (CC) & $11 \%$ & $32.2 \%$ & $56.8 \%$ \\
Exploration (EX) & $15.3 \%$ & $41.5 \%$ & $43.2 \%$ \\
Exploitation (EP) & $9.8 \%$ & $38.5 \%$ & $51.7 \%$ \\
\hline
\end{tabular}

Table 3 shows the percentage of TC, RC, CC, EX, and EP. The level of TC, RC, and CC was categorized based on responses from the instrument as follows: Low-Level $1=1$ (Never) to 2 (Rarely); Medium $=3$ (Sometimes); and High $=4$ (Often) to 5 (Very Often). Levels for EX and EP were categorized based on responses from the instrument, as follows: Low Level $=1$ (to a very small extent) to 2 (to a small extent); Medium $=3$ (to a moderate extent); and High $=4$ (to a large extent) to 5 (to a very large extent). The results reveal that, in the context of SMEs, employees perceive that they have a medium (32.7\%) to high (52.9\%) level of TC, a high (64.1\%) level of RC, a medium (32.2\%) to high (56.8\%) level of CC, a medium (41.5\%) to high level of exploration $(43.2 \%)$, and a medium $(38.5 \%)$ to high (51.7\%) level of exploitation. This demonstrates the involvement of ambidextrous and crafting behavior among SME managers.

\subsection{Structural Model Assessment}

After verifying reliability and validity, the next step is to test for the statistical significance of the structural models. A nonparametric procedure referred to as a bootstrapping procedure is carried out using the smart PLS-SEM to examine the significance of the model. The bootstrapping procedure calculates the value of predictive accuracy $\left(\mathrm{R}^{2}\right)$, predictive relevance $\left(\mathrm{Q}^{2}\right)$, and path modeling. Moreover, the bootstrapping procedure evaluates the model fitness by calculating the value of standardized root mean square (SRMR). The value of SRMR (standardized root mean square) calculated for the structural model used in this study is 0.079 , within the acceptable range of 0 to 1 [67]. Figure 2 shows the model extracted through the bootstrapping procedure.

Figure 2 shows the direct and indirect effect of exploration and exploitation (i.e., EP and EX) on perceived business performance (BP), through the mediation of job crafting. Model testing using the bootstrapping procedure shows that the independent variables (EX and EP) have a positive and highly significant direct impact on BP $(\beta=0.170, p$-value $=0.001$, and $\beta=0.180, p$-value $=0.000<0.01)[18]$. The indirect effects of each path are shown in Table 4 below.

Table 4 shows the specific indirect effects of the independent variables on the dependent variable through the mediators. The results reveal that TC $(p$-value $=0.000<0.01)$ and CC $(p$-value $=0.001<0.01)$ mediate the relationship between EX and BP. Similarly, the results indicate that TC $(p$-value $=0.002<0.01)$ and CC $(p$-value $=0.001<0.01)$ mediate the relationship between EP and BP. 


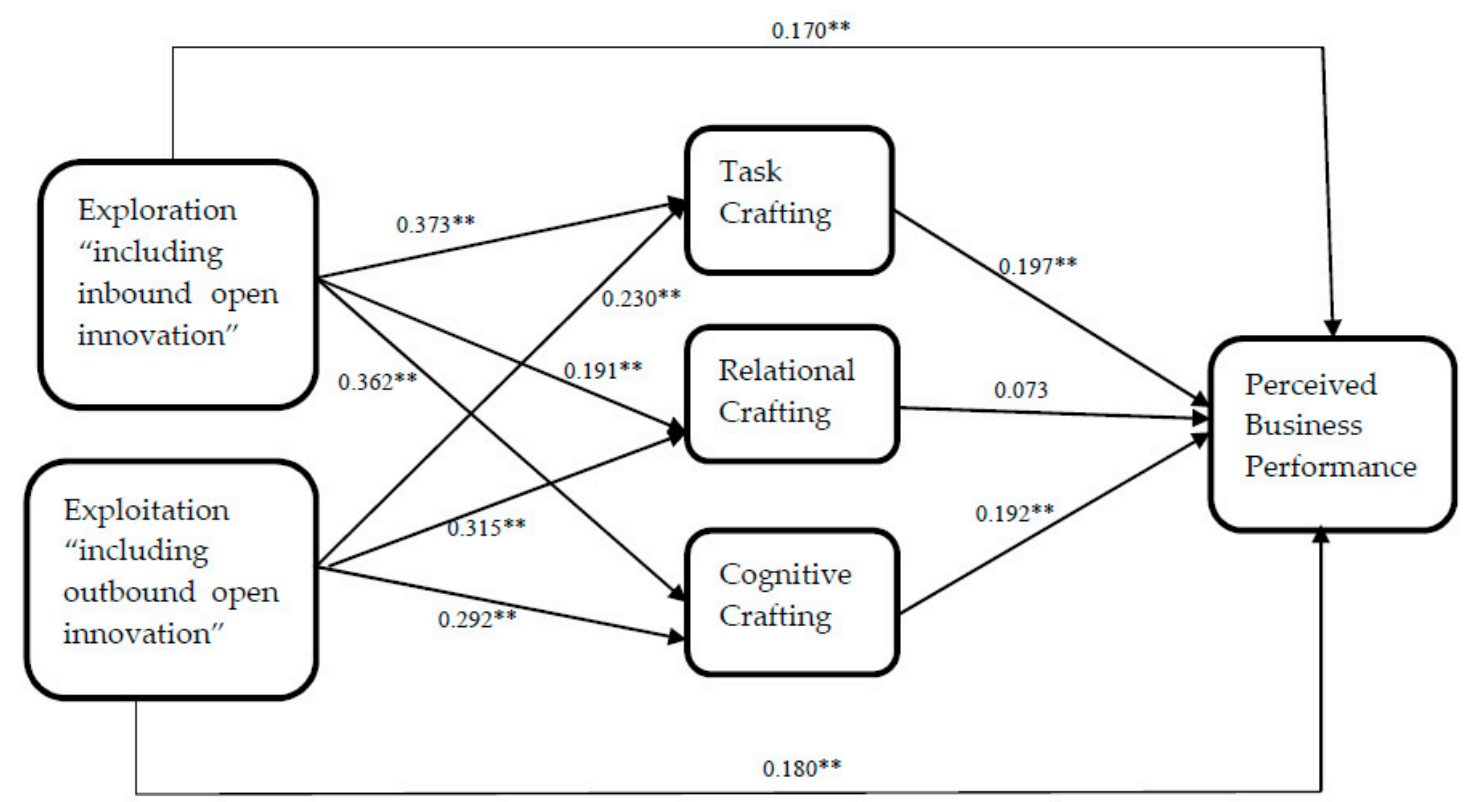

Figure 2. PLS-SEM model. ${ }^{* *} p$-value significant at $<0.01$ level.

Table 4. Testing of the multiple mediations structural model.

\begin{tabular}{|c|c|c|c|}
\hline \multirow{3}{*}{ Effects } & \multirow{3}{*}{ Estimates } & \multirow{2}{*}{\multicolumn{2}{|c|}{$\begin{array}{c}\text { Bootstrapping }{ }^{\mathrm{a}} \\
\text { Bias Corrected CI 95\% }\end{array}$}} \\
\hline & & & \\
\hline & & Lower Bound & Upper Bound \\
\hline \multicolumn{4}{|l|}{ Total Effects } \\
\hline $\mathrm{EX}->\mathrm{BP}$ & $0.327 * *$ & 0.227 & 0.425 \\
\hline $\mathrm{EP}->\mathrm{BP}$ & $0.305^{* *}$ & 0.206 & 0.393 \\
\hline \multicolumn{4}{|l|}{ Direct Effects } \\
\hline $\mathrm{EX}->\mathrm{BP}$ & $0.170 * *$ & 0.112 & 0.208 \\
\hline $\mathrm{EP}->\mathrm{BP}$ & $0.180 * *$ & 0.082 & 0.175 \\
\hline \multicolumn{4}{|c|}{ Specific Indirect Effects } \\
\hline $\mathrm{EX}->\mathrm{TC}->\mathrm{BP}$ & $0.073^{* *}$ & 0.039 & 0.117 \\
\hline $\mathrm{EX}->\mathrm{RC}->\mathrm{BP}$ & 0.014 & 0.000 & 0.035 \\
\hline $\mathrm{EX}->\mathrm{CC}->\mathrm{BP}$ & $0.070 * *$ & 0.033 & 0.110 \\
\hline $\mathrm{EP}->\mathrm{TC}->\mathrm{BP}$ & $0.045^{* *}$ & 0.023 & 0.081 \\
\hline $\mathrm{EP}->\mathrm{RC}->\mathrm{BP}$ & 0.023 & -0.001 & 0.051 \\
\hline $\mathrm{EP}->\mathrm{CC}->\mathrm{BP}$ & $0.056^{* *}$ & 0.027 & 0.092 \\
\hline
\end{tabular}

Note. ${ }^{a} 500$ bootstrap samples; ${ }^{* *} p$-value significant at $<0.01$ level.

\subsection{Multi-Group Analysis}

PLS multi-group analysis (PLS-MGA) was applied to examine the indirect, specific effects between male and female managers to test the proposed hypotheses. Table 5 reports the specific indirect effects of the multiple mediation model moderated by gender. 
Table 5. Gender differences in the multiple mediation structural model.

\begin{tabular}{|c|c|c|c|c|c|c|}
\hline \multirow{4}{*}{ Specific Indirect Effects } & \multirow{3}{*}{\multicolumn{2}{|c|}{$p$-Values }} & \multicolumn{4}{|c|}{ Bootstrapping ${ }^{\text {a }}$} \\
\hline & & & \multicolumn{4}{|c|}{ Bias Corrected CI 95\% } \\
\hline & & & \multicolumn{2}{|c|}{ Lower } & \multicolumn{2}{|c|}{ Upper } \\
\hline & Female & Male & Female & Male & Female & Male \\
\hline $\mathrm{EX}->\mathrm{TC}->\mathrm{BP}$ & 0.657 & 0.00 ** & -0.018 & 0.042 & 0.079 & 0.140 \\
\hline $\mathrm{EX}->\mathrm{RC}->\mathrm{BP}$ & 0.471 & 0.069 & -0.135 & 0.015 & 0.023 & 0.080 \\
\hline $\mathrm{EX} \rightarrow \mathrm{CC}->\mathrm{BP}$ & 0.174 & 0.023 * & -0.010 & 0.012 & 0.235 & 0.099 \\
\hline $\mathrm{EP}->\mathrm{TC}->\mathrm{BP}$ & 0.295 & $0.009 * *$ & -0.037 & 0.004 & 0.197 & 0.049 \\
\hline $\mathrm{EP}->\mathrm{RC}->\mathrm{BP}$ & 0.552 & 0.026 * & 0.103 & 0.008 & 0.018 & 0.070 \\
\hline $\mathrm{EP}->\mathrm{CC}->\mathrm{BP}$ & 0.055 & 0.028 * & 0.027 & 0.008 & 0.263 & 0.082 \\
\hline
\end{tabular}

Note. ${ }^{\text {a }} 500$ bootstrap samples ${ }^{*} p$-value: significant at $<0.05$ level; ${ }^{* *}$ highly Significant at $<0.01$.

Table 5 reports gender differences while examining the mediating effect of the dimensions of job crafting (TC, RC, and CC) between the two dimensions of manager ambidexterity (EX and EP) and business performance. The results indicate gender differences in the mediation of TC (Females $p=0.66>0.05$, Males $p=0.00,<0.01$ ), and CC (Females $p=0.17>0.05$, Males $p=0.02<0.05$ ) between the relationship of EX and BP. Conversely, gender differences are not witnessed ( $p$-values $>0.05$ for both male and female employees) in the mediating role of RC between the two dimensions of manager ambidexterity (EX and EP) and BP. Similarly, the results indicate that gender differences are seen while evaluating the mediation of TC (Females $p=0.30>0.05$, Males $p=0.009,<0.01$ ); RC (Females $p=0.55>0.05$, Males $p=0.03<0.05$ ); and CC (Females $p=0.06>0.05$, Males $p=0.028<0.05$ ) between the relationship of EP and BP.

Table 6 shows that all hypotheses are supported except for H1b. We can infer that male managers, when involved in ambidextrous activities, tend to alter the nature of their tasks and use their cognitive abilities to enhance business performance. The results also reveal that there is no difference in RC between male and female managers while they are exploring opportunities. However, while exploiting opportunities, male managers tend to alter their behavior by reaching out to stakeholders differently compared to female managers. This may be due to societal barriers/issues. We can infer that, if female employees are involved in decision-making and their views are valued, they tend to develop relationships; otherwise, they feel reluctant to develop relationships in the workplace. Overall, the results reveal that male managers tend to redesign their tasks while conducting explorative and exploitative activities that lead to improved business performance. The findings indicate a need for practical measures to identify the reasons why female managers tend to be less involved in explorative and exploitative activities.

Table 6. Summary of the hypotheses.

\begin{tabular}{lc}
\hline \multicolumn{1}{c}{ Hypotheses } & Results \\
\hline Hypothesis 1a: The relationship between EX and BP through TC will be moderated by gender. & Supported \\
Hypothesis 1b: The relationship between EX and BP through RC will be moderated by gender. & Not Supported \\
Hypothesis 1c: The relationship between EX and BP through CC will be moderated by gender. & Supported \\
Hypothesis 2a: The relationship between EP and BP through TC will be moderated by gender. & Supported \\
Hypothesis 2b: The relationship between EP and BP through RC will be moderated by gender. & Supported \\
Hypothesis 2c: The relationship between EP and BP through CC will be moderated by gender. & Supported \\
\hline
\end{tabular}

\section{Discussion: Open Innovation, Job Crafting, Gender and Business Performance}

This study sought to investigate job crafting's role as a mediator between manager ambidexterity and SMEs' business performance. The study also aimed to investigate the proposed conceptual model with an overarching view of gender as a moderator. 
The findings of the present study revealed similar results to previous studies $[17,23,50]$. The results indicate that managers' explorative and exploitative activities positively impact SMEs' business performance. While [22] indicates that females are more oriented towards ambidextrous activities, this study's results contradict his findings, but are consistent with [18], who revealed that male managers are involved in explorative and exploitative activities. The results of the present reveal that, in comparison to their male counterparts, female managers score lower in inbound open innovation or explorative activities. Besides this, female managers tend to possess lesser flexibility and utilize limited cognitive abilities in altering the tasks that may be needed to enhance business performance. Similarly, the results also reveal that, compared to male managers, female managers are involved less in outbound open innovation or exploitation activities. Moreover, male managers tend to score high in flexibility to offer newer products or services by altering their tasks, interacting with individuals or businesses outside and using their cognitive abilities, which may prove helpful in enhancing business performance.

The different results can be attributed to differences in the size, extent of formalization, span of control, organizational culture, and organization's country of origin. Kanter [68] argues that gender differences arise in organizations due to their structure rather than the individual characteristics of males and females. He further argues that "While organizations were being defined as sex-neutral machines, masculine principles were dominating their authority structures." As far as smaller organizations are concerned, the authority and lesser participation of females in some services such as aviation, construction, iron and steel, gems and jewelry, sports goods, transportation, and many more create a gender-neutral environment that fails to distinguish the proactive, explorative, and exploitative behavior among male and female employees. This holds true in the South Asian context, where female participation is minimal, especially in senior managerial positions, and is mostly dominated by males. This argument is supported by SFT; when males and females have similar levels of endowment, they may achieve similar levels of firm performance. However, some of the differences may also exist due to the strategies male and female managers adopt, which could vary in terms of cultural, social, and environmental factors within organizations, rather than the origin of the geographical origin of the business [18].

The findings regarding the mediating role of job crafting between the relationship of manager ambidexterity and business performance indicate that only TC and CC mediate this link. Meanwhile, gender differences reveal that when male managers search for new opportunities and evaluate different options, they tend to adapt by learning new skills through TC and CC, which enhances SMEs' business performance. Similarly, male managers are more aware of company policies and try to achieve goals by understanding the prevailing circumstances. As a result, they attempt to achieve goals by utilizing their cognitive abilities and intentionally alter their tasks to improve SMEs' business performance. These findings are consistent with the recent results [19].

Overall, the results of the study reveal that male employees are proactively involved in crafting their jobs. We can infer that male employees concentrate more on specific work tasks, alter those tasks intentionally, and enjoyably accomplish them. This, in turn, positively enhances SMEs' business performance. However, this may be influenced by the comparative lack of opportunities and endowments available to female employees.

\subsection{Practical Implications}

These results provide important insights into the benefits of fewer formalized structures, as seen in SMEs. Decentralized decision-making helps managers explore and exploit opportunities in creative ways. SMEs should realize that the employees can redesign their work tasks proactively and arrange their multiple tasks, utilizing their abilities and considering how the opportunities can be explored and exploited.

An essential aspect is the finding that males and females possess different competencies that may prove beneficial in terms of their appropriate utilization for SMEs. Policymakers should recognize 
that males' inherent dominance in the South Asian context has to be rectified by providing equal opportunities for employment and participation to female managers. Pakistan has the most significant SME labor force, especially in the services sector. We should realize that the female population constitutes $48.76 \%$ of the total population. This highlights the significant role that the female population can play in participating in the largest employability sector in Pakistan. Moreover, while the government of Pakistan has introduced schemes for young entrepreneurs, it should also focus on the substantial number of female populations who can be given opportunities to participate as a potential workforce. This is particularly important for senior managerial positions and could be encouraged by providing appropriate support for females to enroll in higher education degree programs.

\subsection{Limitations and Future Directions}

Although the present study contributes to the existing literature by identifying the link between manager ambidexterity and business performance through job crafting and moderated by gender, it is still subject to some limitations. Firstly, the study only examined service sector SMEs operating in Pakistan. Thus, future researchers should focus on the manufacturing sector or other unexplored sectors. The findings are limited to an emerging country, i.e., Pakistan, so future studies could be conducted in Western contexts.

Secondly, only one demographic characteristic was incorporated in the model, i.e., gender difference. We recommend that future researchers identify the conceptual model moderated by age groups and manager education levels. Thirdly, the data were collected at the same time for the independent, mediating, and dependent variables. As a result, causality between the variables is difficult to determine. Future studies need to use a panel design to collect data at multiple points in time to unfold the causal relationship between the variables.

\section{Conclusions}

This study provides interesting results that emphasize the role that managers can play in positively influencing SMEs' business performance by engaging in explorative and exploiting activities by redesigning their job (job crafting). The results also reveal that, currently, it is predominantly male managers in SMEs who explore and exploit opportunities by intentionally altering tasks to enhance business performance.

Author Contributions: Conceptualization, F.H.A.; methodology, F.H.A., and M.A.; software, F.H.A., and H.F.A.; validation, F.H.A. and M.A.H.; formal analysis, F.H.A. and M.A.; investigation, F.H.A. and M.A.H.; writing-original draft preparation, F.H.A., M.A. and S.Z.M.; writing-review and editing, S.Z.M.; visualization, F.H.A., and M.A.H.; project administration and data collection, H.F.A. All authors have read and agreed to the published version of the manuscript.

Funding: This research received no external funding.

Conflicts of Interest: The authors declare no conflict of interest.

\section{References}

1. Chesbrough, H.W. Open Innovation: The New Imperative for Creating and Profiting from Technology; Harvard Business Press: Boston, MA, USA, 2003.

2. March, J.G. Exploration and Exploitation in Organizational Learning. Organ. Sci. 1991, 2, 71-87. [CrossRef]

3. Hafkesbrink, J.; Schroll, M. Ambidextrous Organizational and Individual Competencies in Open Innovation: The Dawn of a new Research Agenda. J. Innov. Manag. 2014, 2, 9-46. [CrossRef]

4. Hodgkinson, I.R.; Ravishankar, M.N.; Fischer, M. The ambidextrous manager: What role does culture play? J. Bus. Strategy 2017, 38, 3-9. [CrossRef]

5. Hinteregger, C.; Durst, S.; Temel, S.; Yesilay, R.B. The impact of openness on innovation in SMEs. Int. J. Innov. Manag. 2019, 23, 1950003. [CrossRef]

6. Torchia, M.; Calabrò, A. Open innovation in SMEs: A systematic literature review. J. Enterprising Cult. 2019, 27, 201-228. [CrossRef] 
7. Brunswicker, S.; Ehrenmann, F. Managing open innovation in SMEs: A good practice example of a German software firm. Int. J. Ind. Eng. Manag. 2013, 4, 33-41.

8. Adler, P.S.; Goldoftas, B.; Levine, D. Flexibility Versus Efficiency? A Case Study of Model Changeovers in the Toyota Production System. Organ. Sci. 2007, 10, 43-68. [CrossRef]

9. Heracleous, L.; Wirtz, J. Singapore Airlines' Balancing Act. Harv. Bus. Rev. 2010, 88, 145-149.

10. Stadler, C. The Four Principles of Enduring Success. Harv. Bus. Rev. 2007, 85, 62-72.

11. Ajayi, O.M.; Odusanya, K.A.; Morton, S. Stimulating employee ambidexterity and employee engagement in SMEs. Manag. Decis. 2017, 55, 662-680. [CrossRef]

12. Hafkesbrink, J.; Bachem, C.; Kulenovic, D. Contextual Ambidexterity and Individual Competencies for Exploration and Exploitation in Small and Medium Sized Enterprises-Empirical Results from Case Studies in the German New Media Industry. In Flexibilität und Stabilität in der Verlagsund Medienbranche_Konzepte beidhändiger Unternehmensstrategien; Hafkesbrink, J., Shire, K., Eds.; Schriften zu Kooperations- und Mediensystemen: Köln, Germany, 2013; Volume 34, pp. 65-170.

13. Deci, E.L.; Ryan, R.M. The "What" and "Why" of Goal Pursuits: Human Needs and the Self-Determination of Behavior. Psychol. Inq. 2000, 11, 227-268. [CrossRef]

14. Grant, A.M. Relational job design and the motivation to make a prosocial difference. Acad. Manag. Rev. 2007, 32, 393-417. [CrossRef]

15. Sheldon, K.M.; Turban, D.B.; Brown, K.G.; Barrick, M.R.; Judge, T.A. Applying Self-Determination Theory to organizational research. Res. Pers. Hum. Resour. Manag. 2015, 22, 357-393.

16. Luu, T.T.; Dinh, K.; Qian, D. Ambidextrous leadership, entrepreneurial orientation, and job crafting: The moderating role of organizational social exchange. Eur. Bus. Rev. 2019, 31, 260-282. [CrossRef]

17. Tan, M.; Liu, Z. Paths to success: An ambidexterity perspective on how responsive and proactive market orientations affect SMEs' business performance. J. Strateg. Mark. 2014, 22, 420-441. [CrossRef]

18. Zuraik, A.; Kelly, L.; Perkins, V. Gender differences in innovation: The role of ambidextrous leadership of the team leads. Manag. Decis. 2020, 58, 1475-1495. [CrossRef]

19. Kalyan, V.S.; Manjula, S.; Kondeti, C.; Padma, T.M.; Suresh, S.; Pratap, K.V.N.R. Making our job hospitable-Assessment of job-crafting behavior among dental academic faculty in South India. J. Indian Assoc. Public Health Dent. 2018, 16, 149-153.

20. Kim, G.-N.; Lee, Y.-M. Towards high performance organization: The impacts of job characteristics and job crafting. Int. J. U E Serv. Sci. Technol. 2016, 9, 85-100. [CrossRef]

21. Hooff, M.V.; Hooft, E.V. Boredom at work: Proximal and distal consequences of affective work-related boredom. J. Occup. Health Psychol. 2014, 19, 348-359. [CrossRef]

22. Alghamdi, F. Ambidextrous leadership, ambidextrous employee, and the interaction between ambidextrous leadership and employee innovative performance. J. Innov. Entrep. 2018, 7, 1. [CrossRef]

23. Torres, J.P.; Drago, C.; Aqueveque, C. Knowledge inflows effects on middle managers' ambidexterity and performance. Manag. Decis. 2015, 53, 2303-2320. [CrossRef]

24. Rudolph, C.W.; Katz, I.M.; Lavigne, K.N.; Zacher, H. Job Crafting: A Meta-Analysis of Relationships with Individual Differences, Job Characteristics, and Work Outcomes. J. Vocat. Behav. 2017, 102, 112-138. [CrossRef]

25. Slemp, G.R.; Vella-Brodrick, D.A. Optimising Employee Mental Health: The Relationship between Intrinsic Need Satisfaction, Job Crafting, and Employee Well-Being. J. Happiness Stud. 2014, 15, 957-977.

26. Petrou, P.; Demerouti, E.; Xanthopoulou, D. Regular versus cutback-related change: The role of employee job crafting in organizational change contexts of different nature. Int. J. Stress Manag. 2016, 24, 62-85. [CrossRef]

27. Zhang, D.; Linderman, K.; Schroeder, R.G. The moderating role of contextual factors on quality management practices. J. Oper. Manag. 2012, 30, 12-23.

28. Lee, K.; Kim, Y.; Joshi, K. Organizational memory and new product development performance: Investigating the role of organizational ambidexterity. Technol. Forecast. Soc. Chang. 2017, 120, 117-129. [CrossRef]

29. Keller, T.; Weibler, J. What It Takes and Costs to Be an Ambidextrous Manager: Linking Leadership and Cognitive Strain to Balancing Exploration and Exploitation. J. Leadersh. Organ. Stud. 2015, 22, 54-71. [CrossRef]

30. Jansen, J.J.P.; George, G.; van den Bosch, F.A.J.; Volberda, H.W. Senior Team Attributes and Organizational Ambidexterity: The Moderating Role of Transformational Leadership. J. Manag. Stud. 2008, 45, 982-1007. 
31. Cao, Q.; Simsek, Z.; Zhang, H. Modelling the Joint Impact of the CEO and the TMT on Organizational Ambidexterity. J. Manag. Stud. 2010, 47, 1272-1296. [CrossRef]

32. Gibson, C.B.; Birkinshaw, J. The antecedents, consequences, and mediating role of organizational ambidexterity. Acad. Manag. J. 2004, 47, 209-226.

33. Raisch, S.; Birkinshaw, J. Organizational Ambidexterity: Antecedents, Outcomes, and Moderators. J. Manag. 2008, 34, 375-409. [CrossRef]

34. Hill, S.A.; Birkinshaw, J. Ambidexterity and survival in corporate venture units. J. Manag. 2014, 40, $1899-1931$. [CrossRef]

35. Lubatkin, M.H.; Simsek, Z.; Ling, Y.; Veiga, J.F. Ambidexterity and Performance in Small-to Medium-Sized Firms: The Pivotal Role of Top Management Team Behavioral Integration. J. Manag. 2006, 32, 646-672. [CrossRef]

36. Caniëls, M.; Neghina, C.; Schaetsaert, N. Ambidexterity of employees: The role of empowerment and knowledge sharing. J. Knowl. Manag. 2017, 21, 1098-1119. [CrossRef]

37. Minbaeva, D.B.; Mäkelä, K.; Rabbiosi, L. Linking HRM and knowledge transfer via individual-level mechanisms. Hum. Resour. Manag. 2012, 51, 387-405. [CrossRef]

38. Junni, P.; Sarala, R.M.; Taras, V.; Tarba, S.Y. Organizational ambidexterity: A meta-analysis. Acad. Manag. Perspect. 2013, 27, 299-312. [CrossRef]

39. Kobarg, S.; Wollersheim, J.; Welpe, I.M.; Spörrle, M. Individual Ambidexterity and Performance in the Public Sector: A Multilevel Analysis. Int. Public Manag. J. 2015, 20, 226-260. [CrossRef]

40. Reagans, R.; Argote, L.; Brooks, D. Individual Experience and Experience Working Together: Predicting Learning Rates from Knowing Who Knows What and Knowing How to Work Together. Manag. Sci. 2005, 51, 869-881. [CrossRef]

41. Caniëls, M.C.J.; Veld, M. Employee ambidexterity, high performance work systems and innovative work behaviour: How much balance do we need? Int. J. Hum. Resour. Manag. 2016, 30, 565-585. [CrossRef]

42. Moses, T.; Goossens, A. Plants for human health: Greening biotechnology and synthetic biology. J. Exp. Bot. 2017, 68, 4009. [CrossRef]

43. Raisch, S.; Birkinshaw, J.; Probst, G.; Tushman, M. Organizational ambidexterity: Balancing exploitation and exploration for sustained performance. Organ. Sci. 2009, 20, 685-695. [CrossRef]

44. Bierly, P.E.; Daly, P.S. Alternative knowledge strategies, competitive environment, and organizational performance in small manufacturing firms. Entrep. Theory Pract. 2007, 31, 493-516. [CrossRef]

45. Dolz, C.; Iborra, M.; Safon, V. Improving the likelihood of SME survival during financial and economic crises: The importance of TMTs and family ownership for ambidexterity. BRQ Bus. Res. Q. 2019, 22, 119-136. [CrossRef]

46. Damanpour, F. Organizational Size and Innovation. Organ. Stud. 1992, 13, 375-402. [CrossRef]

47. Dar, M.S.; Ahmed, S.; Raziq, A. Small and Medium-Size Enterprises in Pakistan: Definition and critical issues. Pak. Bus. Rev. 2017, 19, 46-70.

48. Clear, F.; Dickson, K. Teleworking practice in small and medium-sized firms: Management style and worker autonomy. New Technol. Work Employ. 2005, 20, 218-233. [CrossRef]

49. Wrzesniewski, A.; Dutton, J.E. Crafting a Job: Revisioning Employees as Active Crafters of Their Work. Acad. Manag. Rev. 2001, 26, 179-201. [CrossRef]

50. Cao, Q.; Gedajlovic, E.; Zhang, H. Unpacking Organizational Ambidexterity: Dimensions, Contingencies, and Synergistic Effects. Organ. Sci. 2009, 20, 781-796. [CrossRef]

51. Griffin, M.A.; Neal, A.; Parker, S.K. A New Model of Work Role Performance: Positive Behavior in Uncertain and Interdependent Contexts. Acad. Manag. J. 2007, 50, 327-347. [CrossRef]

52. World Bank. Gender Equality and Development. In 'Overview' in World Development Report; World Bank: Washington, DC, USA, 2012.

53. Black, N. Social Feminism; Cornell University Press: Ithaca, NY, USA, 1989.

54. Inmyxai, S.; Takahashi, Y. Determining the applicability of feminist theories by examining the mediation and moderation effects on non-economic performance in Lao micro, small, and medium-sized enterprises. Gend. Manag. Int. J. 2011, 26, 457-482. [CrossRef]

55. Miraglia, M.; Cenciotti, R.; Alessandri, G.; Borgogni, L. Translating self-efficacy in job performance over time: The role of job crafting. Hum. Perform. 2017, 30, 254-271. [CrossRef] 
56. SMEDA. State of SMEs in Pakistan. 2020. Available online: https://smeda.org/index.php?option=com content\&view=article\&id=7:state-of-smes-inpakistan (accessed on 16 September 2020).

57. Natter, E. The Role of an Operations Manager. 2019. Available online: https://smallbusiness.chron.com/roleoperations-manager-14234.html (accessed on 16 September 2020).

58. Abid, G.; Ahmed, S.; Elahi, N.S.; Ilyas, S. Antecedents and mechanism of employee well-being for social sustainability: A sequential mediation. Sustain. Prod. Consum. 2020, 24, 79-89. [CrossRef]

59. Mom, T.J.; Van Den Bosch, F.A.; Volberda, H.W. Investigating Managers' Exploration and Exploitation Activities: The Influence of Top-Down, Bottom-Up, and Horizontal Knowledge Inflows. J. Manag. Stud. 2007, 44, 910-931. [CrossRef]

60. Niessen, C.; Weseler, D.; Kostova, P. When and why do individuals craft their jobs? The role of individual motivation and work characteristics for job crafting. Hum. Relat. 2016, 69, 1287-1313. [CrossRef]

61. Weseler, D.; Niessen, C. How job crafting relates to task performance. J. Manag. Psychol. 2016, 31, $672-685$. [CrossRef]

62. Mattila, A.S.; Enz, C.A. The role of emotions in service encounters. J. Serv. Res. 2002, 4, 268-277. [CrossRef]

63. Hair, J.F.; Hult, G.T.M.; Ringle, C.M.; Sarstedt, M. A Primer on Partial Least Squares Structural Equation Modeling (PLS-SEM), 2nd ed.; Sage Publications: Thousand Oaks, CA, USA, 2016.

64. Fornell, C.; Larcker, D.F. Evaluating Structural Equation Models with Unobservable Variables and Measurement Error. J. Mark. Res. 1981, 18, 39-50. [CrossRef]

65. Diamantopoulos, A.; Siguaw, J.A. Introducing LISREL: A Guide for the Uninitiated; Sage: London, UK, 2000.

66. Henseler, J.; Ringle, C.M.; Sarstedt, M. A new criterion for assessing discriminant validity in variance-based structural equation modeling. J. Acad. Mark. Sci. 2015, 43, 115-135. [CrossRef]

67. Hooper, D.; Coughlan, J.; Mullen, M.R. Structural equation modeling: Guidelines for determining model fit. Electron. J. Bus. Res. Methods 2008, 6, 53-60.

68. Kanter, R.M. Men and Women of the Corporation; Basic Books: New York, NY, USA, 1977.

(C) 2020 by the authors. Licensee MDPI, Basel, Switzerland. This article is an open access article distributed under the terms and conditions of the Creative Commons Attribution (CC BY) license (http://creativecommons.org/licenses/by/4.0/). 